\title{
Predictors of Adherence to Inhaled Medications
}

\author{
John C. Huetsch, $M D^{7}$ and David H. Au, MD, MSC ${ }^{2}$ \\ 'Johns Hopkins School of Medicine, Baltimore, MD, USA; ${ }^{2}$ University of Washington, Seattle, WA, USA.
}

$\mathrm{J}$ Gen Intern Med 28(6):759

DOI: $10.1007 / \mathrm{s} 11606-013-2383-7$

(c) Society of General Internal Medicine 2013 in patients with COPD. ${ }^{3}$ We agree that other features of the patient-physician interaction may be important determinants of medication adherence, both in COPD and in other chronic illnesses, and that further studies should assess which aspects of the patient-physician interaction have a significant impact on adherence.

Corresponding Author: David H. Au, MD, MSc; University of Washington, 1100 Olive Way, Seattle, WA 98101, USA (e-mail:dau@uw.edu).

\section{REFERENCES}

1. Huetsch JC, Uman JE, Udris EM, Au DH. Predictors of adherence to inhaled medications among veterans with COPD. J Gen Intern Med. 2012;27:1506-12.

2. Cecere LM, Slatore CG, Uman JE, Evans LE, Udris EM, Bryson CL, et al. Adherence to long-acting inhaled therapies among patients with chronic obstructive pulmonary disease. COPD. 2012;9:251-8.

3. George J, Kong DC, Thoman R, Stewart K. Factors associated with medication nonadherence in patients with COPD. Chest. 2005;128:3198-204. 